\title{
Characterization of the porcine nutrient and taste receptor gene repertoire in domestic and wild populations across the globe
}

Elizabete C da Silva ${ }^{1,2+}{ }^{+}$Nadia de Jager ${ }^{3+}$, William Burgos-Paz ${ }^{1}$, Antonio Reverter ${ }^{4}$, Miguel Perez-Enciso ${ }^{1,5^{*}}$ and Eugeni Roura ${ }^{3 *}$

\begin{abstract}
Background: The oral GPCR nutrient/taste receptor gene repertoire consists of the Tas $1 r$ family (sweet and umami tastes), the Tas2r family (bitter taste) as well as several other potential candidate sensors of amino acids, peptones and fatty acids. Taste/nutrient receptors play a fundamental role in survival through the identification of dietary nutrients or potentially toxic compounds. In humans and rodents some variations in taste sensitivity have been related to receptor polymorphisms. Some allelic variants, in turn, have been linked to the adaptation to specific geographical locations and dietary regimes. In contrast, the porcine taste/nutrient receptor repertoire has been only partially characterized and limited information on genetic variation across breeds and geographical location exists.

The present study aims at filling this void which in turn will form the bases for future improvements in pig nutrition.

Results: Our results show that the pig oral repertoire of taste/nutrient receptors consists of at least 28 receptor genes with significant transcription measured for 27 . When compared to humans and rodents, the porcine gene sequences encoding sensors for carbohydrates, amino acids and fatty acids were highly conserved whilst the bitter taste gene family (known as Tas2rs) showed high divergence. We identified 15 porcine Tas2rs of which 13 are orthologous to human sequences. The single nucleotide polymorphism (SNP) sequence analysis using 79 pig genomes, representing 14 different breeds/populations, revealed that the Tas $2 r$ subset had higher variability (average $\pi=2.8 \times 10^{-3}$ ) than for non-bitter taste genes $\left(\pi=1.2-1.5 \times 10^{-3}\right)$. In addition, our results show that the difference in nutrient receptor genes between Asian and European breeds accounts for only a small part of the variability, which is in contrast with previous findings involving genome wide data.

Conclusions: We have defined twenty-eight oral nutrient sensing related genes for the pig. The homology with the human repertoire is high for the porcine non-bitter taste gene repertoire and low for the porcine Tas2r repertoire. Our data suggests that bitter taste is a plastic trait, possibly associated with the ability of pigs to adapt to diverse environments and that may be subject to balancing selection.
\end{abstract}

Keywords: Pig, Nutrition, GPCR, Taste receptor, Bitter, T1R, T2R, SNPs, Population genomics

\footnotetext{
* Correspondence: miguel.perez@uab.es; e.roura@uq.edu.au

${ }^{\dagger}$ Equal contributors

${ }^{1}$ Centre for Research in Agricultural Genomics (CRAG), CSIC-IRTA-UAB-UB,

08193 Bellaterra, Spain

${ }^{3}$ Centre for Nutrition and Food Sciences, The University of Queensland,

St. Lucia 4067, Australia

Full list of author information is available at the end of the article
}

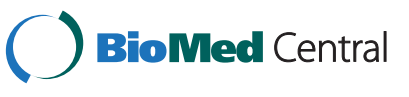

(C) 2014 da Silva et al.; licensee BioMed Central Ltd. This is an Open Access article distributed under the terms of the Creative Commons Attribution License (http://creativecommons.org/licenses/by/4.0), which permits unrestricted use, distribution, and reproduction in any medium, provided the original work is properly credited. The Creative Commons Public Domain Dedication waiver (http://creativecommons.org/publicdomain/zero/1.0/) applies to the data made available in this article, unless otherwise stated. 


\section{Background}

The pig, Sus scrofa, appeared in South East Asia 4.2 million years ago $(\mathrm{M})$ [1], colonizing a wide range of habitats thereafter including Europe and North Africa. European and Asian wild boars are estimated to have diverged $1.2 \mathrm{M}$ [2]. The wild boar is among the first of the domesticated livestock species, an event that occurred approximately 8,000-10,000 BC both in Europe and in Asia in independent events $[3,4]$. Today, thanks to the intense modern breeding and selection programmes, the pig is one of the most economically important domestic species worldwide providing a relatively cheap source of dietary protein for humans. The species Sus scrofa is highly variable at both the DNA and phenotypic levels and there are 200-300 pig breeds currently recognized $[5,6]$. Consequently, the study of pig diversity from different ecosystems and breeds including wild and domestic populations may uncover phenotype-genotype relationships of high evolutionary and adaptive physiology relevance. In particular, dietary adaptation through taste sensory mechanisms is emerging as a major evolutionary selection pressure $[7,8]$. Taste receptors (hereinafter referred to as TRs) and their genes (Tasrs, nomenclature consistent with the review by Bachmanov and Beauchamp [9]) are known to monitor the presence of dietary compounds in the oral cavity. With the exception of the salty and sour tastes, all other candidate receptors known to date related to taste and nutrient sensing belong to the family of G-protein coupled receptors (GPCRs). Salty and sour perceptions seem to be related to ligand gated transmembrane channels. More specifically, these channels consist of tetrameric epithelial sodium channels (involving three genes $E N a C_{\alpha, \beta, \gamma}$ ) for salty; and dimeric hydrogen gated channels (involving two genes PKD1L3 and PKD2L1) for sour [9]. Both multimeric transmembrane channels are quite ubiquitous and do not seem to be specific to sensory cells, hence have not been included in this study. On the other hand, the taste system includes two main families of GPCRs. Family 1 is related to simple sugars and some L-amino acids present in the diet (hereinafter referred to as Tas1rs). Family 2 is part of the sensory mechanism to identify potentially toxic compounds and elicits bitter taste (hereinafter referred to as Tas2rs) [9]. Other GPCRs have been related to nutrient sensing in the oral cavity and include the sensing of amino acids and peptones (mGluR1, mGluR4, GPRC6A, CaSR and GPR92), medium and long chained saturated and unsaturated fatty acids (GPR40, GPR41, GPR43, GPR84 and GPR120) [9,10]. Overall, the oral chemosensory gene repertoire can be potentially divided into those receptors identifying nutrients (e.g. sugars, amino acids and fatty acids) which in turn would elicit a positive hedonic sensation, and receptors responding to potential undesirable substances (e.g. plat-derived toxic compounds), which in turn would trigger a repulsive response (bitter).

More precisely, the Tas $2 \mathrm{r}$ family seems to play a role of particular relevance in species evolution across mammalian species [7]. In a genomic analysis involving 54 vertebrate species (including 41 mammals) Li and Zhang [8] found evidence that the Tas $2 r$ diversity was associated with the adaptation to the presence of dietary toxins among other selective forces. In addition, genetic selection related to domestication may also be an important driver to dietary adaptations [11]. Thus, we hypothesize that the cluster of Tas2rs across pig breeds from different geographical origins and/or selection pressure (such as the one observed in commercial breeds) will show a higher presence of polymorphisms than the non-bitter nutrient/ taste sensing genes.

The genome of the Duroc breed of swine was sequenced by the International Swine Genome Sequencing Consortium (SGSC) and the information was made publically available in 2010 [12]. In 2013 a reviewed annotation was released which identified part of the porcine taste receptor repertoire [2]. A total of 25,322 genes (including 566 pseudo genes) are currently annotated in the Sus scrofa assembly 10.2 (Ensembl database v. 75). However, the nutrient sensing and taste receptor gene repertoire in pigs has only been partially described $[2,13,14]$ and their diversity across the Sus scrofa population remains unknown.

The objective of our study is to update the current porcine genome annotation regarding nutrient sensors or taste receptors and study their diversity. Here we quantify and compare the variability in nutrient and taste receptor genes across different domestic breeds and wild boars spread around the world. Given the potential role of bitter perception in environmental adaptations, we will test the hypothesis that the Tas $2 r$ repertoire in pigs has a higher diversity than the non-bitter taste receptors.

\section{Results}

\section{Prediction of the porcine taste and nutrient receptor gene repertoire}

In order to identify the Tasr repertoire in the porcine genome, we carried out BLAST searches using known human $(n=37)$ and mouse $(n=47)$ mRNA sequences. We excluded putative sour and salty taste receptor genes from the analysis because of their multimeric nature, ubiquitous expression (i.e. not unique to taste sensory cells) and not being GPCRs. The genes were grouped based on nutrient sensing: sugars (Tas1r2 and Tas1r3); amino acids and peptones (Tas1r1, Tas1r3, mGluR1, mGluR4, GPRC6A, CaSR and GPR92); fatty acids (GPR40, GPR41, GPR43, GPR84 and GPR120); and bitter compounds (the Tas $2 r$ sub-family). Figure 1 shows the homology percentage between the known TASRs and Tasrs in human and mouse, respectively 


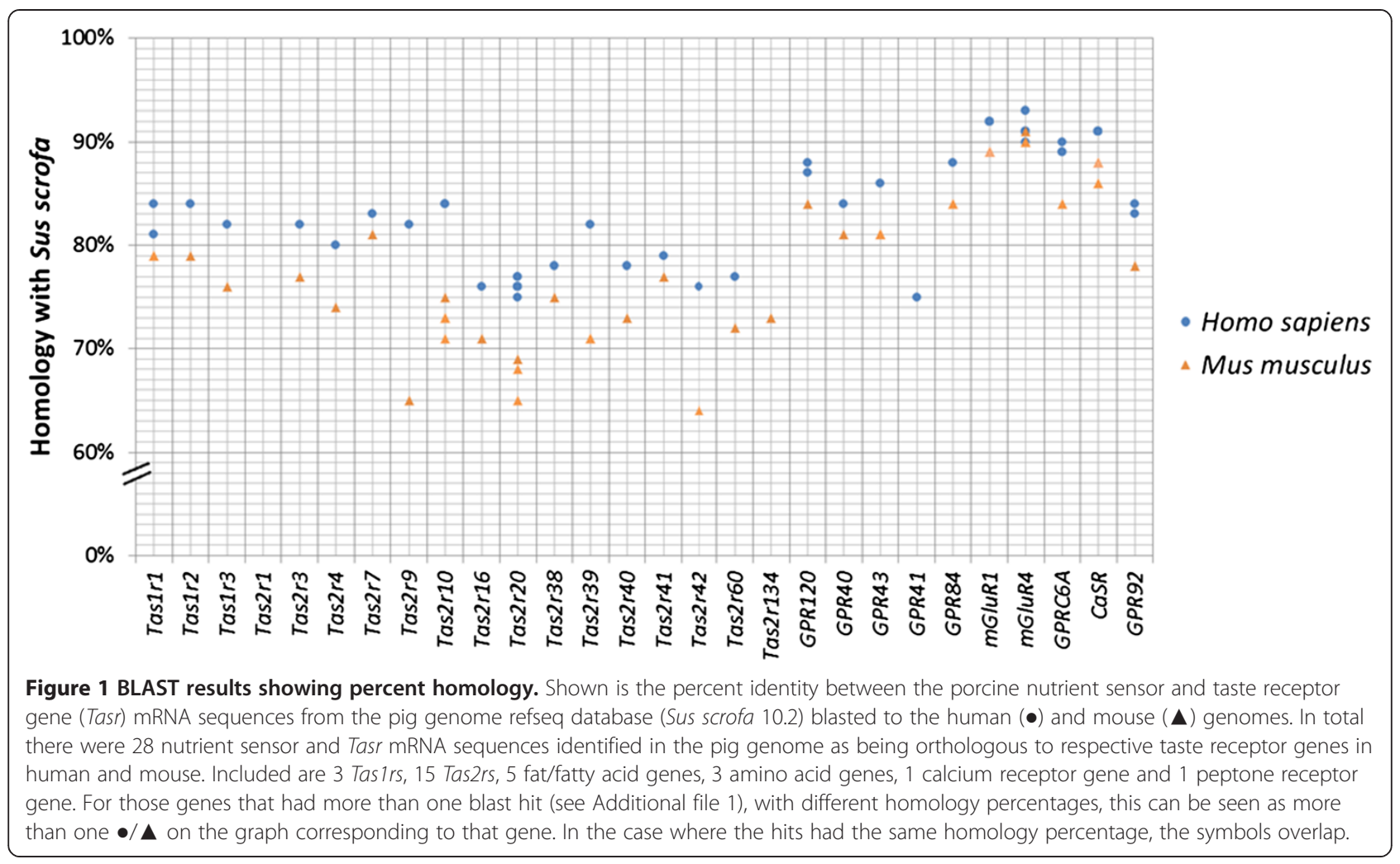

compared to those found to match in the pig genome. We have included 15 Tas $2 r$ s, for which the current annotation denotes 11 of these to be protein coding and 4 to be pseudo genes (Additional file 1). The porcine Tas $2 r$ repertoire appears to differ significantly from human and mouse repertoires. For example, seven human TAS2R (numbers 14, 19, 20 31, 43, 45, 46 and 50) and three mouse Tas $2 r$ (numbers 120, 123 and 117) show high homology $(\geq 65 \%)$ to only a single pig bitter receptor pseudo gene, Tas2r20. In contrast, the pig Tas $2 r 1$ and Tas2r134 have no human orthologs.

Of all the 28 porcine genes studied, the cluster of genes sensing amino acids showed the highest homologies to their human orthologs ranging from $90 \%$ to $93 \%$ (Additional file 1). The peptone receptor, GPR92, had $84 \%$ homology with its human ortholog. With the exception of the GPR41 (75\% homology), the fatty acid receptors and the three Tas1rs showed medium to high identities between the two species ranging from $82 \%$ to $88 \%$. Finally, the lowest homologies identified between pig and human Tasrs were amongst the porcine Tas2r family and GPR41. In addition, when comparing the pig Tasr repertoire to the mouse, the gene homologies follow a similar pattern.

\section{Expression of the porcine GPCR nutrient sensor and taste} receptor gene repertoire in circumvallate papillae

We determined whether the candidate porcine Tasrs were transcribed into mRNA in tongue circumvallate papillae using real time PCR. Following standard procedures, total RNA was extracted from porcine papillae and reversed transcribed into cDNA before carrying out the PCR assays (see methods). Figure 2 shows the relative in vivo gene expression levels of all the genes identified in our study as constituting the pig Tasr repertoire in pig circumvallate papillae. All Tasrs identified were significantly expressed, with the exception of Tas $2 r 40$ which was not measured; due to it not satisfying our criteria of being a protein coding Tas $2 r$ (refer to discussion). The results showed that GPR92 and Tas2r134 had the highest and CaSR the lowest relative gene expression levels. Of the Tas1r subfamily, Tas1r3 is expressed significantly $(\mathrm{P}<0.01)$ higher than Tas1r1 and Tas1r2. Amongst the Tas2r repertoire, we observed the highest expression levels for Tas $2 r 20$ and Tas2r134. In contrast, Tas2r1, Tas2r16 and Tas $2 r 60$ were found to have a relatively low gene expression level. Two of the fatty acid sensors had higher $(\mathrm{P}<0.01)$ expression levels (GPR120 and GPR84) compared to the other three (GPR40, GPR41 and GPR43). Among the group of genes with specificity to amino acid sensing, CaSR showed a significantly $(\mathrm{P}<0.01)$ lower abundance than the rest.

\section{Species wide variant discovery}

Out of all 28 gustatory genes identified, we carried out a comprehensive variability analysis of the sequence of 21 genes that were present in the current porcine assembly (build 10.2). The seven genes excluded from the analysis 


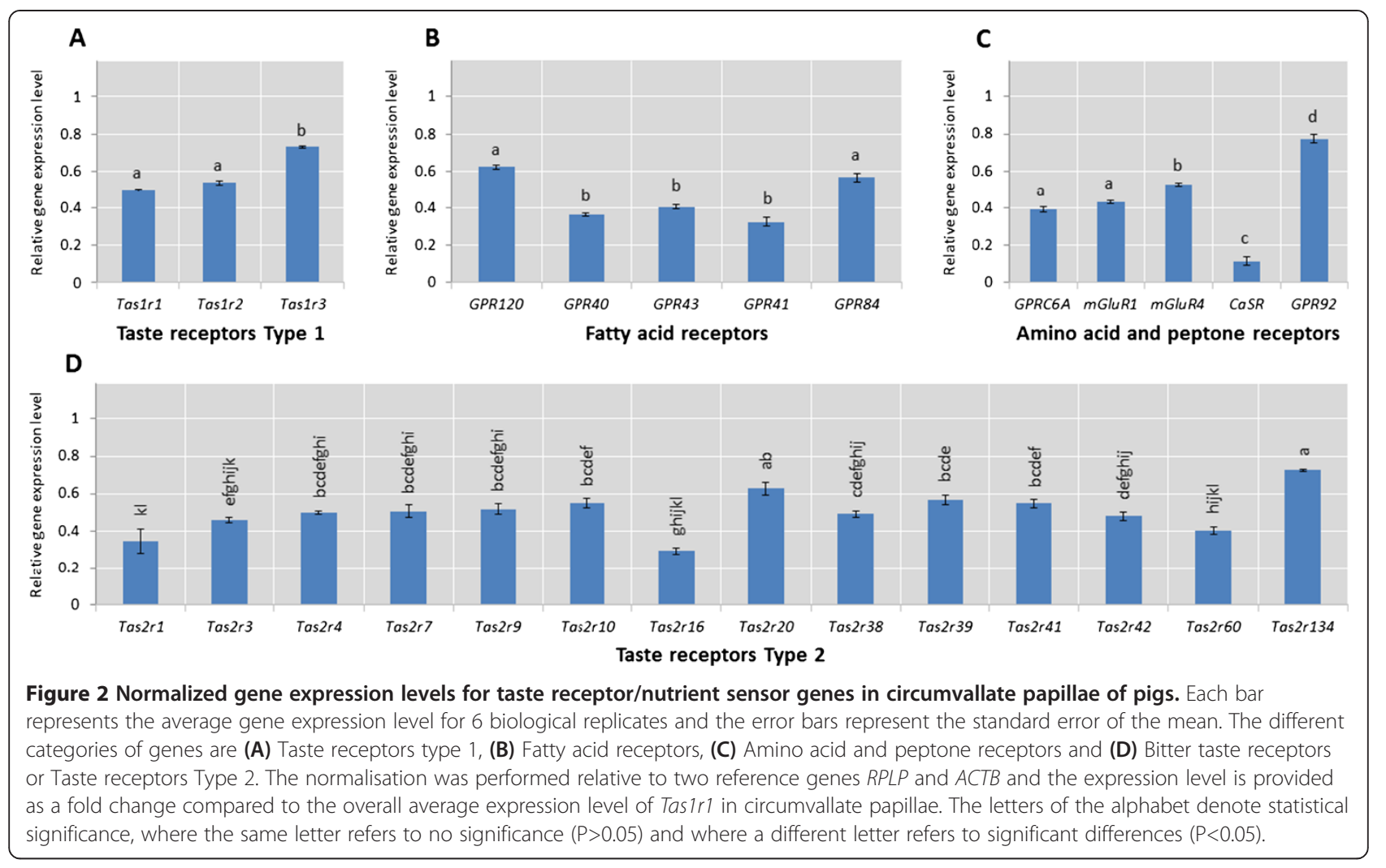

were Tas1r2, Tas2r1, Tas2r134, Tas2r3, Tas2r40, Tas2r4 and GPR92, because they were either not annotated or annotated in contigs and not in any of the 18 porcine autosomes or sex chromosomes.

Using high throughput sequencing data from 79 samples distributed worldwide (methods, Table 1), a total of 12,235 SNPs were found across all 21 genes and $10 \mathrm{~kb}$ flanking regions (Table 2). The average rate of transitions vs. transversions was $t_{i} / t_{v}=2.35$, similar to the genome wide rate in pigs [15] and similar to that found in other mammalian species [16,17]. A total of 8,962 SNPs $(73 \%)$ had been previously assigned reference SNP numbers available in the Single Nucleotide Polymorphism Database (dbSNP v. 138). Out of 8,259 SNPs positioned between 5' and 3' UTRs, 7,963 were in introns, 296 in exons in the protein coding regions of the genes, and only 17 in UTRs (12 in 5'UTR and 5 in 3'UTR). Among functional coding SNPs, one stop lost, one stop gained, 167 synonymous and 110 non-synonymous mutations were found. Additional file 2 contains all SNPs with reference SNP ID number or rs ID if available, reference and alternative allele, amino acid change; SIFT score for non-synonymous changes, and frequency of each variant, globally and by population. The 3,274 novel SNPs have been reported to dbSNP (reference ss1432164463).

We used Sorting Intolerant From Tolerant (SIFT) tool [18], as implemented in Ensembl Variant Effect Predictor, to predict amino acid changes that may affect protein function of nsSNPs subset from dbSNP (http://www.ncbi. nlm.nih.gov/SNP/) [19]. While these in silico tools are not always reliable, they do provide guidelines as to what SNPs to prioritize in follow up functional studies. Out of 110 nsSNPs for the investigated Tasrs, it was possible to predict tolerance index for 59 SNPs, of which 11 (rs320709106, rs342189509, rs342228000, rs345262132, rs339482728, rs325274060, rs330666697, rs323728911, rs318787211 from dbSNPs; and 5:63977077 and 1:21476805 from novel SNPs) presented a tolerance index score below 0.05 , and can therefore be considered potentially deleterious to protein function (Additional file 2). In general, and in agreement with the potentially deleterious nature of these mutations, these alleles were rare and mostly present in a single population; they are probably recent mutations that have not been purged yet. However, a few interesting exceptions exist. For instance, nsSNP rs330666697 (Tas1r1) was at intermediate frequency in Asian domestics (minimum allele frequency MAF $=0.43$ ) and is present in international and in American village pigs.

\section{Patterns of nucleotide variation}

A worrying aspect of shotgun Next Generation Sequence (NGS) data is the fact that coverage is a quasi-random process and it is therefore unlikely that all samples have enough depth and quality to be analysed. In our data, we 
Table 1 The Groups of pig breeds included in this study

\begin{tabular}{|c|c|c|c|c|}
\hline Group & Breeds & Country & Code & $N(n)$ \\
\hline \multirow[t]{5}{*}{ International (INT) } & Large White & NA & LW & $15(1)$ \\
\hline & Landrace & Several countries & $L R$ & 5 \\
\hline & Duroc & Several countries & DU & 4 \\
\hline & Pietrain & Several countries & $\mathrm{Pl}$ & 5 \\
\hline & Hampshire & Several countries & $\mathrm{HS}$ & 2 \\
\hline European domestic & Iberian & Spain & $\mathrm{IB}$ & $4(4)$ \\
\hline European wild boar & wild boar & Netherlands, Switzerland, France and Spain & EUWB & $9(2)$ \\
\hline Asian domestic & Meishan, Xiang, Jiangquhai and Wuzhishan & China & ASD & 8 \\
\hline Asian wild boar & Wild boar & Japan, South and North China, East Russia & ASWB & $6(1)$ \\
\hline Creole & Creole, Ossabaw, Yucatan & Peru, Cuba, Argentine and United State & $C R$ & $14(13)$ \\
\hline Brazilian & Brazilian $^{a}$ & Brazil & $\mathrm{BR}$ & $3(3)$ \\
\hline No group & Tamworth & United Kingdom & TW & $1(1)$ \\
\hline No group & 'Manchado Jabugo' & Spain & MJ & $1(1)$ \\
\hline Outgroup & Sumatra's wild boar & Sumatra & SWB & 2 \\
\hline
\end{tabular}

Provided are the details on geographical distribution, code and number of individual genomes (N) of the 79 pigs analyzed.

aPiau, Monteiro and Moura breeds, $n=$ Quantify of new samples sequenced in this study.

found an average of $20 \%$ missing data rate (Table 2), which makes it necessary to use methods that account for this. The missing rate was as high as $50 \%$ for two genes, CaSR and Tas1r3, and these were removed from further analyses. Consequently, for the rest of the work we discuss the results relevant only to the 19 loci remaining.

Nucleotide diversity per nucleotide and global fixation indices $\left(\mathrm{F}_{\mathrm{ST}}\right)$ were calculated using mstatpop (unpublished, available at http://bioinformatics.cragenomica.es/ numgenomics/people/sebas/software/software.html), which provides unbiased estimates of basic population genetic statistics even at high missing rates [18] (Table 3). Species wide, average gene variability was $2.1 \times 10^{-3}$, comparable to that found in the flanking regions (average $1.8 \times 10^{-3}$ ). Synonymous variability rate $\left(\pi_{\mathrm{s}}\right)$ was $3.8 \times 10^{-3}$ on average whereas non-synonymous rate $\left(\pi_{\mathrm{a}}\right)$ was three times lower (average $\pi_{\mathrm{a}}=1.21 \times 10^{-3}$ ), in agreement with most results in the literature [18] and consistent with a prevailing purifying selection model.

Among gene regions, nucleotide diversity $\left(\pi_{\mathrm{g}}\right)$ ranged from $0.5 \times 10^{-3}$ in GPRC6A to $4.7 \times 10^{-3}$ in Tas $2 r 42$. Interestingly, bitter taste genes exhibited higher nucleotide diversity on gene regions (average $\pi_{\mathrm{g}}=2.6 \times 10^{-3}$ ) than in intergenic regions (average $\pi_{t}=1.9 \times 10^{-3}$ ). The opposite was observed in the remaining groups of genes, which showed greater diversity in the complete region, i.e., gene sequence plus $10 \mathrm{~kb}$ flanking regions (averages $\pi_{\mathrm{t}}=1.9 \times 10^{-3}$ in gene region and $2.1 \times 10^{-3}$ in complete region). Both fatty acid and amino acid receptors showed lower gene nucleotide diversity than bitter taste receptors (Tables 3 and 4). Overall, the gene variability, especially for the bitter taste receptors, are higher than normally reported for the pig species genome wide, which are in the order of $1.2 \times 10^{-3}$ for international pig breeds and $0.7 \times 10^{-3}$ for Iberian pigs [2,20].

As mentioned, the ratio of non-synonymous to synonymous variants $\left(\omega=\pi_{a} / \pi_{s}\right)$ was smaller than 1 in all genes (Table 3), indicating prevalent purifying selection. Some extreme cases were observed. For instance, we did not find any non-synonymous SNPs in GPR120 or any synonymous polymorphisms in Tas $2 r 9$. Four genes (Tas2r10, Tas2r39, Tas2r41, and GPRC6A) presented $\omega$ values higher than 0.5 and smaller than 1 , likely due to weak purifying selection (Table 3 ).

Estimates of nucleotide diversity varied greatly between genes and between populations (Table 4 and Additional file 3). Asian domestic (ASD) and Asian wild boar (ASWB) exhibited a high within-population variability, with average value $\pi_{\mathrm{g}}=2.3 \times 10^{-3}$. Iberian population was the least variable $\left(\pi_{\mathrm{g}}=1.2 \times 10^{-3}\right)$, whereas the American village and Brazilian pigs presented the highest levels of diversity $\pi_{\mathrm{g}}=2.6 \times 10^{-3}$ and $\pi_{\mathrm{g}}=2.9 \times 10^{-3}$, respectively which seem to reflect their admixed ancestry [18]. We also analyzed the nucleotide diversity by gene groups in each population (Table 4). Brazilian, Creole and EUWB population showed the highest variability for Tas $2 r s$, mainly when we analyzed only the gene regions (averages $\pi_{\mathrm{g}}=3.6 \times 10^{-3} \pm 1.0 \times 10^{-3}$, $\pi_{\mathrm{g}}=3.3 \times 10^{-3} \pm 0.8 \times 10^{-3}$ and $\pi_{\mathrm{g}}=3.1 \times 10^{-3} \pm 0.8 \times 10^{-3}$, respectively). Iberian population, in comparison to other populations, showed almost two times lower nucleotide diversity for this same gene group (average $\pi_{\mathrm{g}}=2.0 \times 10^{-3} \pm 0.4 \times 10^{-3}$, Table 4). Therefore, except in the Iberian pig where we analyzed the highly inbred strain 'Guadyerbas' [21], the rest of porcine populations analyzed exhibit considerable variability in these genes. 
Table 2 General information about the pig taste receptor genes used in this study

\begin{tabular}{|c|c|c|c|c|c|c|c|c|c|c|c|c|c|c|c|c|c|}
\hline \multirow[b]{2}{*}{ Gene group } & \multirow[b]{2}{*}{ Genes } & \multirow[b]{2}{*}{ exon* } & \multirow[b]{2}{*}{ Chr. } & \multirow{2}{*}{$\begin{array}{l}\text { Total region } \\
\text { Coordinates (bp) }\end{array}$} & \multirow[b]{2}{*}{ SNPs } & \multicolumn{3}{|c|}{ Gene region } & \multicolumn{9}{|c|}{ SNP distribution by class and functional consequences } \\
\hline & & & & & & Coordinates (bp) & $\%$ miss & SNPs & Intergenic & Exon & Intron & 5'UTR & 3'UTR & Stop lost & Stop gained & Sy & $\mathrm{Ns}$ \\
\hline \multirow[t]{10}{*}{ Bitter } & Tas $2 r 20$ & 1 & 5 & $63894140-63915054$ & 310 & $63904140-63905054$ & 10.98 & 13 & 297 & 13 & - & - & - & - & - & 5 & 8 \\
\hline & Tas2r9 & 1 & 5 & 63971739-63982674 & 229 & 63976739-63977674 & 9.10 & 6 & 223 & 6 & - & - & - & - & - & 0 & 6 \\
\hline & Tas2r10 & 1 & 5 & $63958146-63971725$ & 266 & 63965446-63966375 & 12.12 & 9 & 257 & 9 & - & - & - & - & - & 2 & 7 \\
\hline & Tas $2 r 42$ & 1 & 5 & $63857091-63878041$ & 257 & $63867091-63868041$ & 10.06 & 17 & 240 & 17 & - & - & - & - & - & 9 & 8 \\
\hline & Tas2r16 & 1 & 18 & $25873452-25894354$ & 474 & $25883452-25884354$ & 10.25 & 16 & 458 & 16 & - & - & - & - & - & 8 & 8 \\
\hline & Tas2r38 & 1 & 18 & $8347518-8368525$ & 79 & $8357518-8358525$ & 16.13 & 21 & 58 & 21 & - & - & - & - & - & 11 & 10 \\
\hline & Tas2r39 & 1 & 18 & 7348848-7369855 & 310 & 7358848-7359855 & 10.08 & 28 & 282 & 28 & - & - & - & - & 1 & 8 & 19 \\
\hline & Tas $2 r 41$ & 1 & 18 & 7008806-7029729 & 88 & 7018806-7019729 & 20.90 & 18 & 70 & 18 & - & - & - & - & - & 6 & 12 \\
\hline & Tas2r60 & 1 & 18 & 7035247-7056597 & 110 & 7045247-7046597 & 11.59 & 24 & 86 & 14 & 10 & - & - & - & - & 10 & 4 \\
\hline & Tas $2 r 7$ & 1 & 5 & $63982692-63996080$ & 254 & $63985142-63986080$ & 8.82 & 10 & 244 & 10 & - & - & - & - & - & 5 & 5 \\
\hline \multirow[t]{6}{*}{ Aminoacid } & Tas $1 r^{a}$ & 6 & 6 & $58109541-58116535$ & 34 & $58111612-58115907$ & 57.76 & 17 & 17 & 14 & 3 & 1 & 4 & - & - & 8 & 1 \\
\hline & mGluR4 & 10 & 7 & $34829241-34938071$ & 2344 & $34839241-34928071$ & 40.00 & 1976 & 368 & 36 & 1940 & 8 & - & - & - & 26 & 2 \\
\hline & GPRC6A & 3 & 1 & $50121244-50146085$ & 253 & $50131244-50136085$ & 11.74 & 41 & 212 & 6 & 35 & - & - & - & - & 3 & 3 \\
\hline & mGluR1 & 7 & 1 & 21466379-21824964 & 5671 & $21476379-21814964$ & 16.07 & 5421 & 250 & 20 & 5401 & 3 & 1 & - & - & 15 & 1 \\
\hline & $\operatorname{CaSR}^{\mathrm{a}}$ & 6 & 13 & $147897932-147940283$ & 345 & $147907932-147935070$ & 75.62 & 138 & 208 & 22 & 116 & - & - & - & - & 20 & 2 \\
\hline & Tas1r1 & 7 & 6 & $62349877-62363714$ & 117 & $62350603-62363204$ & 31.62 & 112 & 5 & 13 & 99 & - & - & 1 & - & 7 & 5 \\
\hline \multirow[t]{6}{*}{ Fatty acids } & GPR40 & 1 & 6 & $40335081-40343065$ & 89 & $40339566-40340468$ & 50.96 & 8 & 81 & 8 & - & - & - & - & - & 4 & 4 \\
\hline & GPR43 & 1 & 6 & $40272039-40293031$ & 243 & $40282039-40283031$ & 40.38 & 11 & 232 & 11 & - & - & - & - & - & 10 & 1 \\
\hline & GPR41 & 1 & 6 & $40323922-40335070$ & 172 & $40333922-40334902$ & 43.46 & 11 & 161 & 11 & - & - & - & - & - & 8 & 3 \\
\hline & GPR120 & 3 & 14 & $114733575-114769008$ & 516 & $114743575-114765158$ & 18.73 & 360 & 156 & 1 & 359 & - & - & - & - & 1 & 0 \\
\hline & GPR84 & 2 & 5 & $20404644-20416116$ & 74 & $20410225-20411195$ & 31.99 & 2 & 72 & 2 & - & - & - & - & - & 1 & 1 \\
\hline & Total & & & $778077+$ & 12235 & $480139+$ & & 8259 & 3977 & 296 & 7963 & 12 & 5 & 1 & 1 & 167 & 110 \\
\hline
\end{tabular}

Details included are the chromosome, start and end position, total SNPs and their distribution by genomic region and functional consequence, and missing data (\%miss). This analysis was performed in 77 pigs (the two Sumatran wild boars are not included).

${ }^{\mathrm{a} G e n e s}$ excluded because of high missing rate, $\mathrm{Sy}=$ Synonymous and $\mathrm{Ns}=$ Nonsynonymous sites. *Number of exons per genes.. + Total length in base pairs for all genes (bp).

The $\%$ of missing data, for every position, was computed as the number of non-callable genotypes, either because of low quality or low depth (a minimum depth of $5 \times$ was required), divided by total number of samples (77). Total missing rate was the average across positions. 
Table 3 Nucleotide diversity per gene

\begin{tabular}{|c|c|c|c|c|c|c|c|c|c|c|}
\hline Gene group & Genes & $\pi_{\mathrm{t}} \pm \mathrm{SE}$ & $\pi_{\text {int }} \pm \mathrm{SE}$ & $\pi_{g} \pm \mathrm{SE}$ & $\pi_{\mathrm{e}} \pm \mathrm{SE}$ & $\pi_{i} \pm S E$ & $\pi_{\mathrm{utr}} \pm \mathrm{SE}$ & $\pi_{s}$ & $\pi_{a} / \pi_{s}$ & $\mathrm{~F}_{\mathrm{ST}}^{\mathrm{a}}$ \\
\hline \multirow[t]{10}{*}{ Bitter } & Tas2r20 & $2.0 \pm 0.6$ & $2.1 \pm 0.5$ & $2.7 \pm 1.2$ & $2.7 \pm 1.2$ & - & - & 5.5 & 0.3359 & $0.28^{*}$ \\
\hline & Tas2r9 & $2.3 \pm 0.7$ & $2.4 \pm 0.7$ & $1.0 \pm 0.6$ & $1.0 \pm 0.6$ & - & - & 0.0 & $\mathrm{NA}^{+}$ & $0.41^{*}$ \\
\hline & Tas2r10 & $1.9 \pm 0.6$ & $2.0 \pm 0.6$ & $0.8 \pm 0.6$ & $0.8 \pm 0.6$ & - & - & 1.0 & 0.6879 & $0.38^{*}$ \\
\hline & Tas2r42 & $2.0 \pm 0.6$ & $1.9 \pm 0.9$ & $4.7 \pm 1.6$ & $4.7 \pm 1.6$ & - & - & 10.0 & 0.3098 & $0.29^{*}$ \\
\hline & Tas2r16 & $3.1 \pm 0.8$ & $3.2 \pm 0.5$ & $2.2 \pm 0.9$ & $2.2 \pm 0.9$ & - & - & 4.9 & 0.2745 & 0.04 \\
\hline & Tas2r38 & $0.7 \pm 0.2$ & $0.5 \pm 0.2$ & $3.6 \pm 1.3$ & $3.6 \pm 1.3$ & - & - & 8.6 & 0.2371 & $0.29^{*}$ \\
\hline & Tas2r39 & $3.0 \pm 0.2$ & $3.0 \pm 0.1$ & $4.2 \pm 1.5$ & $4.2 \pm 1.5$ & - & - & 5.7 & 0.6438 & 0.12 \\
\hline & Tas2r41 & $0.5 \pm 0.2$ & $0.5 \pm 0.2$ & $2.3 \pm 1.0$ & $2.3 \pm 1.0$ & - & - & 3.3 & 0.6041 & $0.29^{*}$ \\
\hline & Tas2r60 & $0.8 \pm 0.2$ & $0.7 \pm 0.2$ & $2.4 \pm 0.9$ & $1.6 \pm 1.0$ & $4.3 \pm 1.6$ & - & 4.8 & 0.0940 & $0.38^{*}$ \\
\hline & Tas2r7 & $2.9 \pm 0.2$ & $3.0 \pm 0.2$ & $1.8 \pm 0.8$ & $1.8 \pm 0.8$ & - & - & 2.8 & 0.5311 & $0.15^{*}$ \\
\hline \multirow[t]{4}{*}{ Amino acids } & mGluR4 & $3.6 \pm 0.5$ & $3.2 \pm 0.3$ & $3.7 \pm 0.4$ & $2.1 \pm 0.6$ & $3.7 \pm 0.4$ & $0.8 \pm 0.7$ & 7.7 & 0.0188 & $0.28^{*}$ \\
\hline & GPRC6A & $1.0 \pm 0.8$ & $1.1 \pm 0.8$ & $0.5 \pm 0.2$ & $0.5 \pm 0.3$ & $0.6 \pm 0.3$ & - & 0.8 & 0.6738 & $0.29^{*}$ \\
\hline & mGluR1 & $2.1 \pm 0.3$ & $1.5 \pm 0.2$ & $2.1 \pm 0.4$ & $0.8 \pm 0.4$ & $2.1 \pm 0.7$ & $3.0 \pm 1.8$ & 3.5 & 0.0007 & $0.18^{*}$ \\
\hline & Tas1R1 & $0.8 \pm 0.3$ & $0.5 \pm 0.8$ & $0.9 \pm 0.3$ & $0.4 \pm 0.3$ & $1.0 \pm 0.3$ & - & 0.8 & 0.3351 & $0.36^{*}$ \\
\hline \multirow[t]{5}{*}{ Fatty acids } & GPR40 & $1.9 \pm 0.3$ & $1.9 \pm 0.4$ & $1.6 \pm 0.8$ & $1.6 \pm 0.8$ & - & - & 3.6 & 0.1940 & $0.23^{*}$ \\
\hline & GPR43 & $1.9 \pm 0.6$ & $2.0 \pm 0.5$ & $1.5 \pm 0.8$ & $1.5 \pm 0.8$ & - & - & 5.1 & 0.0378 & 0.09 \\
\hline & GPR41 & $2.9 \pm 0.6$ & $3.1 \pm 0.5$ & $1.1 \pm 0.7$ & $1.1 \pm 0.7$ & - & - & 3.4 & 0.0986 & $0.26^{*}$ \\
\hline & GPR120 & $1.9 \pm 0.9$ & $1.4 \pm 0.6$ & $2.2 \pm 0.5$ & $0.3 \pm 0.2$ & $2.3 \pm 0.7$ & - & 1.3 & 0.0000 & 0.15 \\
\hline & GPR84 & $0.5 \pm 0.5$ & $0.6 \pm 0.5$ & $0.1 \pm 0.1$ & $0.1 \pm 0.1$ & - & - & 0.1 & 0.3891 & $0.26^{*}$ \\
\hline Average & & $1.9 \pm 0.6$ & $1.8 \pm 0.6$ & $2.1 \pm 0.9$ & $1.7 \pm 0.9$ & $2.3 \pm 0.7$ & $1.9 \pm 1.2$ & 3.8 & & \\
\hline
\end{tabular}

The nucleotide diversity per kilobase is shown by genomic region $(\pi)$, synonymous $\left(\pi_{\mathrm{s}}\right)$ and non-synonymous diversity $\left(\pi_{\mathrm{a}}\right)$ and fixation index $\left(\mathrm{F}_{\mathrm{ST}}\right)$ for each taste receptor gene analyzed in the global pig population excluding the two Sumatran wild boars $(n=77)$.

$\mathrm{SE}=$ standard error, ${ }^{a}=\mathrm{F}_{\mathrm{ST}}$ computed using total region (intergenic and gene), Nucleotide diversity for total $\left(\pi_{\mathrm{t}}\right)$, intergenic $\left(\pi_{\mathrm{int}}\right)$, gene $\left(\pi_{\mathrm{g}}\right.$, included: CDS, intron and UTRs), exonic $\left(\pi_{\mathrm{e}}\right)$, intronic $\left(\pi_{\mathrm{i}}\right)$ and in UTR region $\left(\pi_{\mathrm{utr}}\right) .{ }^{\dagger} \mathrm{Gene}$ without synonymous mutations. ${ }^{*} \mathrm{P}<0.05$, Significance based on 1000 permutations.

\section{Structure and Phylogeography}

Like most domestic species, the pig is arranged in breeds with specific phenotypic differences that are genetically isolated or with limited genetic interchange. High differentiation indices $\left(\mathrm{F}_{\mathrm{ST}}\right)$ are therefore expected in such a structured species with a wide range of distribution and many specialized breeds which prevent the gene flow between them. Not unexpectedly, the global estimate of the $\mathrm{F}_{\mathrm{ST}}$ over all populations per each gene was significantly different from zero, except in Tas2r16, Tas2r39, GPR43 and GPR120 (Table 3) indicating a widespread population differentiation and limited gene flow between populations. By groups, the fatty acid receptors had the lowest degree of differentiation. Significant $\mathrm{F}_{\mathrm{ST}}$ 's ranged from 0.15 to 0.41 (Table 3).

We used Principal Component Analysis (PCA) and STRUCTURE [22] to represent breed and geographic

Table 4 Nucleotide diversity per population

\begin{tabular}{|c|c|c|c|c|c|c|c|c|c|}
\hline \multirow[b]{2}{*}{ Populations* } & \multirow[b]{2}{*}{$\mathrm{N}$} & \multicolumn{2}{|c|}{ Bitter } & \multicolumn{2}{|c|}{ Amino acid } & \multicolumn{2}{|c|}{ Fatty acid } & \multicolumn{2}{|c|}{ All Tasr } \\
\hline & & $\pi_{\mathrm{t}} \pm \mathrm{SE}$ & $\pi_{g} \pm S E$ & $\pi_{\mathrm{t}} \pm \mathrm{SE}$ & $\pi_{g} \pm S E$ & $\pi_{\mathrm{t}} \pm \mathrm{SE}$ & $\pi_{\mathrm{g}} \pm \mathrm{SE}$ & $\pi_{\mathrm{t}} \pm \mathrm{SE}$ & $\overline{\pi_{g} \pm S E}$ \\
\hline International & 31 & $1.8 \pm 0.3$ & $2.8 \pm 0.5$ & $1.9 \pm 0.1$ & $1.7 \pm 0.0$ & $1.4 \pm 0.3$ & $1.0 \pm 0.2$ & $1.8 \pm 0.3$ & $2.2 \pm 0.4$ \\
\hline Iberian & 04 & $1.1 \pm 0.1$ & $2.0 \pm 0.4$ & $0.5 \pm 0.0$ & $0.4 \pm 0.0$ & $0.4 \pm 0.0$ & $0.2 \pm 0.1$ & $0.7 \pm 0.1$ & $1.2 \pm 0.2$ \\
\hline Creole & 14 & $2.7 \pm 0.6$ & $3.3 \pm 0.85$ & $1.8 \pm 0.3$ & $1.7 \pm 0.1$ & $2.5 .0 \pm 0.3$ & $1.8 \pm 0.3$ & $2.5 \pm 0.5$ & $2.6 \pm 0.5$ \\
\hline Brazilian & 03 & $2.8 \pm 0.5$ & $3.6 \pm 1.0$ & $2.1 \pm 0.0$ & $2.1 \pm 0.1$ & $2.9 \pm 0.4$ & $1.7 \pm 0.3$ & $2.8 \pm 0.5$ & $2.90 \pm 0.7$ \\
\hline Asian & 08 & $2.0 \pm 0.3$ & $2.6 \pm 0.7$ & $2.0 \pm 0.1$ & $1.7 \pm 0.0$ & $2.1 \pm 0.4$ & $1.9 \pm 0.5$ & $2.1 \pm 0.4$ & $2.3 \pm 0.6$ \\
\hline Asian WB & 06 & $2.5 \pm 0.6$ & $2.5 \pm 0.60$ & $2.2 \pm 0.3$ & $2.1 \pm 0.1$ & $1.9 \pm 0.2$ & $1.7 \pm 0.4$ & $2.4 \pm 0.5$ & $2.3 \pm 0.6$ \\
\hline European WB & 09 & $2.1 \pm 0.3$ & $3.1 \pm 0.8$ & $1.0 \pm 0.1$ & $0.9 \pm 0.0$ & $0.4 \pm 0.0$ & $0.5 \pm 0.1$ & $1.5 \pm 0.2$ & $1.9 \pm 0.5$ \\
\hline Total & 75 & $2.1 \pm 0.4$ & $2.8 \pm 0.7$ & $1.7 \pm 0.1$ & $1.5 \pm 0.1$ & $1.6 \pm 0.2$ & $1.2 \pm 0.3$ & $2.0 \pm 0.3$ & $2.2 \pm 0.5$ \\
\hline
\end{tabular}

Estimations are per kilobase and were calculated at total $\left(\pi_{t}\right)$ and gene region $\left(\pi_{g}\right)$ by population and gene group. Samples from Tamworth, 'Manchado de Jabugo', and the two Sumatran wild boars are not included.

${ }^{*} P<0.05$, Significance based on 1000 permutations. 
differentiation (Figure 3). We applied PCA at three resolution levels: using all SNPs, using only bitter receptor SNPs, and using only non-synonymous mutations in bitter receptor genes. Both the PCA and STRUCTURE analyses (Figure 3) show a separation between Asian and local European breeds (Iberian) as is typically observed in
mtDNA and at the autosomal level [23,24]. Remarkably, we observed a continuum rather than a clear geographic split between Asia and Europe. For instance, Figure 3A shows the PCA plot with all SNPs from the 19 genes. Here, the first axis explains $16.02 \%$ of the variance, and discriminates between Asia and Europe with international
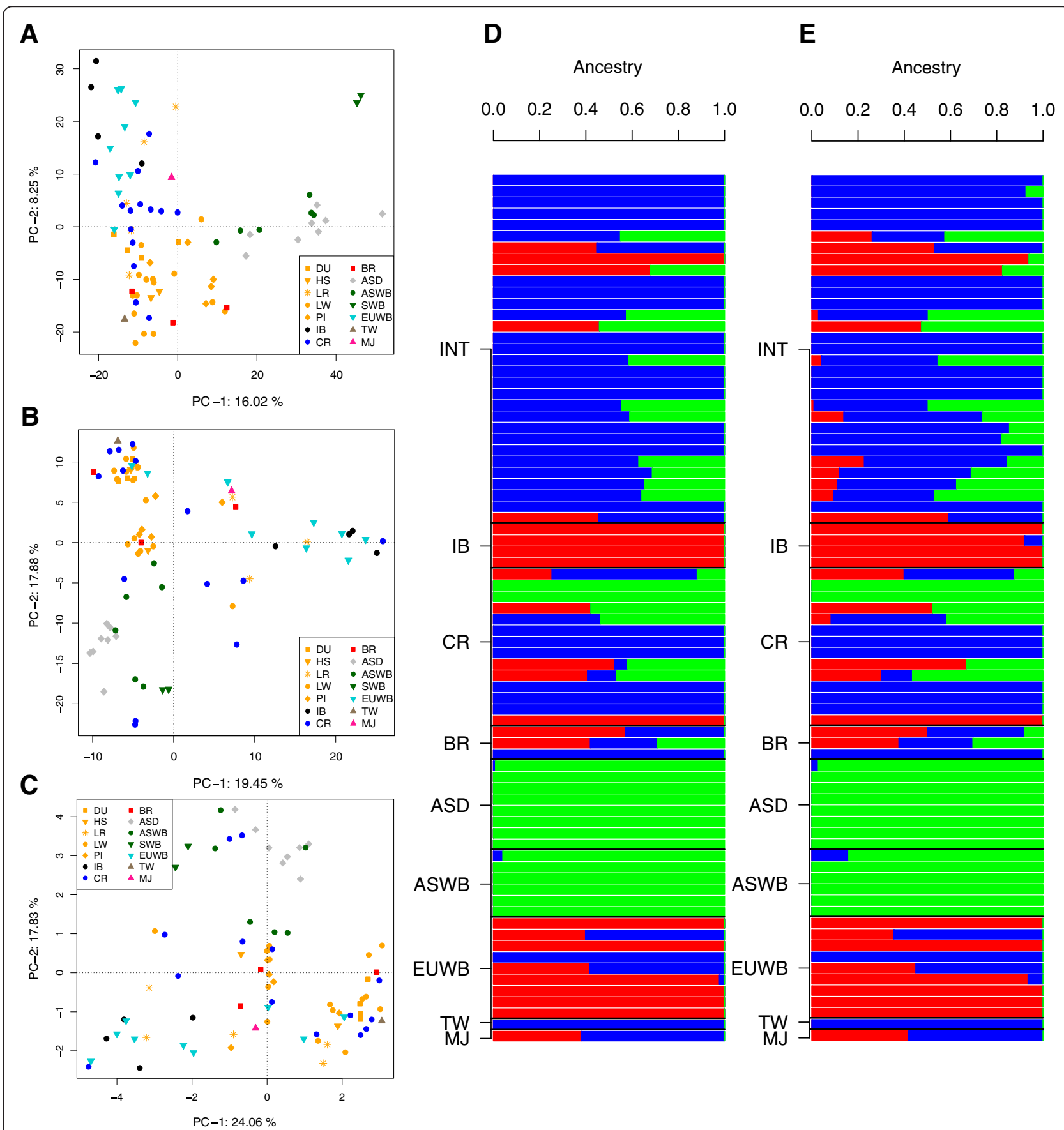

Figure 3 Principal components (PCA) and structure analysis. PCA performed on all SNP data from all 19 genes considered (A) and for a subset different subsets: bitter (B) and non-synonymous SNPs for bitter (C). Structure analyses with full set of SNPs (D) and non-synonymous SNPs from bitter taste receptors (E). Each individual is represented by one vertical line with the proportion of assignment to each cluster shown on the top and the different colours are referent to different clusters: international $(\mathbb{N N T})=$ blue; Asian $($ ASD and ASWB $)=$ green; and European $($ IB and EUWB $)=$ red. Breed and population codes are as in Table 1 . 
breeds clustering in between, but there is a continuum rather than an abrupt divide (e.g. the reader is invited to contrast our Figure 3A with Figure 1 in [25]). The second axis in Figure 3A accounts for $8.25 \%$ variance and separates highly selected breeds from wild boar and non-selected local breeds (Iberian and Chinese, the latter to a lesser extent). This suggests that modern selection has exerted a consistent influence across breeds on the pattern of variability in the pig. Creole and Brazilian pigs tend to fall within the international cluster (Figure 3A). This pattern is exacerbated when only bitter receptor polymorphisms are considered (Figure 3B), with some interesting changes: the first axis (19.45\% of the variance) now separates European Wild Boar and Iberian from the rest, while the second axis (17.88\% variance) distinguishes Asia from the rest. Some international breeds such as Large White are tightly clustered due to their low nucleotide diversity that was smaller than average for this gene groups $\left(\pi_{\mathrm{t}}=1.9 \times 10^{-3} \pm 1.0 \times 10^{-3}\right)$, may be as a result of a selective pressure in commercial breeds on Tasrs. Similar results were observed when only non-synonymous SNPs are employed (Figure 3C).

The STRUCTURE analyses of SNP data from bitter taste receptors suggested that the optimal values of genetic clusters $\mathrm{K}$ were 3 for non-synonymous SNP and 3 to 4 for the full set of SNP (Additional file 2). For $K=3$, Figure 3D and $E$ show a clear separation between Asian (ASD and ASWB), European (IB and EUWB) and international (INT) breeds. Nonetheless, there was a large heterogeneity among individuals within each breed, as is also evident from the PCA graphs. In the Brazilian population (BR), the Piau breed was assigned to the International cluster with $100 \%$ probability, whereas Monteiro and Moura present an admixed fraction of genome from Asian and European origins. Within EUWB, three individuals from the Netherlands and France (WB21M03, WB22F02 and WB25U11) were predicted to hold a high international breed component value ( $>65 \%)$. This could be due either to introgression of international breeds into wild boar or to a lack of differentiation between EUWB and international pigs for these genes. In principle, the introgression hypothesis seems a plausible one, given that admixture events between EUWB and domestics have been repeatedly documented [26,27].

For both set of SNPs the Iberian population was assigned to a cluster of its own, and only one individual had approximately $3 \%$ of its genome composition assigned to the International (INT) cluster. This means that the Iberian population is highly homogeneous, presumably because the individuals studied belong to a highly inbred herd.

\section{Discussion}

Our data defines for the first time the full GPCR nutrient and taste receptor gene repertoire in the pig using human and mouse gene sequence homology analysis and a comprehensive survey of its worldwide variability using shotgun sequence data from 79 pigs. However, it should be noted that current porcine assembly 10.2 and its annotation are still incomplete, where about $8 \%$ of genome is estimated to be missing [2]; further there is a high missing rate in the NGS data as well (Table 2). In addition, novel nutrient sensing genes might be identified in the future. Thus, future studies may be able to uncover a potential hidden fraction of TR and additional TR variability. Within the Tasr repertoire, two main categories have been outlined: those receptors that sense nutrients (the Tas1rs, the amino acid-related receptor genes and the fatty acid receptor genes), also referred here as non-bitter TRs (or non-bitter Tasrs); and those receptors that sense primarily non-nutritional or potentially toxic compounds known as bitter taste receptors (Tas2rs). Admittedly, there is a wide range of non-toxic potential bitter TR ligands including amino acids, peptides or polyphenols amongst many others, but a more detailed discussion on that is outside the scope of the current paper.

Our results from porcine tongue mRNA abundance confirm that the large majority of the genes studied are expressed. The samples were collected by specifically targeting the taste papilla, however, small portions of surrounding structures and cell types (i.e. epithelial cells and underlying muscle tissue), may have also been harvested. Consequently, it is possible (yet unlikely) that the results of the gene transcripts are not related to taste sensory cells. The relative gene expression levels were found to differ significantly $(\mathrm{P}<0.05)$ amongst genes. Tas1r3, Tas2r134 and GPR92 showed the highest whilst Tas $2 r 1$ and CaSR were amongst the lowest expression levels. Within the Tas1rs, the high relative expression level of Tas1r3 compared to the other 2 genes supports previous findings that this gene encodes one part of a dimer for both sweet (Tas2r1+Tas1r3) and umami (Tas1r2 + Tas1r3) taste receptors [28]. The heterodimeric porcine umami receptor (T1r1/T1r3) was the first porcine TR to be sequenced, cloned and fully characterized [29-31]. In agreement with previous reports our data supports the view that pig Tas1rs and mGluR1 have a high homology with the human orthologs [30,32]. Furthermore, the homology of the porcine Tas $2 r 3$ to the human TAS2R3 and to the mouse Tas $2 r 137$ has also previously been reported [33].

Other published work on porcine Tasr expression have been related to the presence of the receptor proteins T1r2 and T1r3 in the small intestine [34], the presence of the amino acid/peptone receptors GPRC6A, GPR92 and CaSR in gastric antrum [35] and seven Tas2rs found to be expressed in five sites of the gastrointestinal tract [36]. However, to our knowledge, these is the first systematic study on porcine Tasr expression related to the oral cavity (circumvallate papillae in the tongue) which 
includes an updated pig taste and nutrient GPCR receptor repertoire. We completed a detailed investigation of the annotation of all the Tasrs resulting in the identification of several incorrect intron-exon boundaries and open reading frames in the current porcine annotation for 11 genes. A correct GFF file with the correct annotation is provided in as Additional file 4. All non-bitter Tasrs found in the pig genome were annotated as complete functional genes, with the exception of GPR84. This gene has a discrepancy in its annotation as NCBI denotes it to be a validated protein coding gene, whereas Ensembl classifies it as a pseudo gene. Our data showing relatively high expression level of this gene seems to further support the NCBI annotation. In contrast, four of the porcine Tas2rs were annotated as pseudo genes.

Mammalian diversity in Tasrs has been related to dietary adaptations [8,37]. Consequently, it is tempting to speculate that the differences in Tasr homologies, particularly related to fatty acid and amino acid sensing, between humans and pigs might be related to diet. The amino acid and peptone receptors showed the highest homologies between pigs and humans (and also mice) which presumably highlights the nutritional relevance of dietary protein across species. Dietary energy is the other macronutrient essential for life and is mainly related to fats and sugars. In our study, the Tasrs for simple carbohydrates (Tas1r2 and Tas1r3) and fatty acids (GPR40, GPR43, GPR84 and GPR120) except GPR41 also resulted in high homologies between the pig, humans and mice. Both humans and pigs are omnivorous species. However, pigs in the wild are foraging animals with a diet consisting roughly $90 \%$ of plantderived foods primarily fruits, roots, leaves and grasses. The relative amount of dietary protein and fats from animal tissues is usually well below $10 \%$ [38] which accounts for an important difference relative to humans who have evolved on dietary habits containing 30 to $80 \%$ of animalderived foods [39]. A higher reliance on plant-derived foods might, in turn, be related to a higher olfactory acuity of pigs compared to humans and other mammals. To date, pigs have the largest of the olfactory gene repertoire of all studied mammalian species. It might be speculated that the lower number of Tas2rs in pigs compared to humans is related to a higher dependency on olfaction. However, the porcine non-bitter (nutrient sensing) Tasr repertoire is very similar in number of genes and sequence homology to the human system. In addition, the lower number of porcine Tas2rs compared to humans, may not imply a decreased sensitivity to dietary bitter compounds since some of the additional human T2R seem to be narrowly tuned and may not even be related to food volatiles [40]. Overall it seems that pigs have a similar gustatory capacity when compared to humans.

Our results show that the highest degree of divergence between pigs and humans is related to the Tas $2 r$ repertoire. Humans have 25 functional TAS2Rs while our study shows that pigs have only 15 of which 4 have been annotated as pseudo genes (Additional file 1). Of the 25 known human TAS2Rs, TAS2R5 had no porcine gene ortholog and seven of the human TAS2Rs had high homology with the porcine Tas $2 r 20$. The Tas $2 r 20$ is currently annotated in NCBI as a pseudo gene; however, we have several reasons in support of this gene being protein coding. We observed that the porcine Tas2r20 shares high homologies of up to $77 \%$ with the human orthologs (Additional file 1). In addition, when translating the mRNA sequence, we predict 311 amino acids as well as 7 conserved transmembrane domains, both attributes consistent with all the other porcine Tas $2 r s$. Furthermore, we have found the gene expression level for Tas2r20 in pig tongue to be similar to other pig Tas2rs. Finally, looking across mammalian species, Tas $2 r 20$ is annotated as a protein coding gene in humans (Homo sapiens), chimpanzee (Pan troglodytes), mouse (Mus musculus), hedgehog (Echinops telfairi) and shrew (Sorex araneus), to name but a few. We cannot conclusively rule out the possibility that the currently annotated Tas $2 r 20$ is in fact a pseudo gene which would indicate that the Tas $2 R 20$ we have found expressed is currently not annotated.

In contrast, we could not find a human ortholog for porcine Tas $2 r 1$ or Tas2r134. Our results show also significant divergence between pigs and mouse such that there was no mouse ortholog for porcine GPR41. In addition, of the 35 known mouse Tas2rs, 6 had no porcine orthologs. Our findings outlining the bitter taste receptor repertoire in the pig are consistent with a previous report by Groenen et al. [2], with the exception of 3 genes; since we have excluded Tas $2 r 7 A$ and Tas $2 r 7 B$ and Tas $2 r 40$. The Gene ID entries in NCBI for Tas $2 r 7 A$ and Tas $2 r 7 B$ have been discontinued and Tas $2 r 7 C$ has been reannotated as Tas $2 R 7$. On the other hand, there is an inconsistency in the annotation of the porcine Tas $2 r 40$ between NCBI and Ensembl. In NCBI, the gene appears shorter than the rest of the protein coding porcine Tas 2 rs while Ensembl denotes 3 exons, a feature not related to Tas2rs. In addition, Tas $2 r 40$ was annotated in a contig and not in any of the porcine chromosomes. However, differences in the Tas $2 r 40$ sequences between commercial and local pig breeds have been recently reported which should warrant further research [41].

T2Rs are involved in detecting potential toxic compounds, consequently a high plasticity at the gene sequence level suggests a role in the adaptation to different ecosystems and feeding regimes [33,42]. Different T2Rs respond to different types of bitter tastants and with different ranges [40]. Therefore it is reasonable to envisage that changes in the types and amounts of bitter compounds encountered in a specific environment may elicit 
specific selection pressures on Tas2rs. Recent evidence has shown a dynamic eco-evolutionary process between the bitter taste system and dietary diversity across vertebrates [8], particularly mammalian species [37]. Li and Zhang 2013 [8] showed that the number of genes of the bitter taste system is species dependent and correlates with the relative amount of plant-derived foods usually present in their diet since most potentially toxic compounds are found in plant tissues. Consequently, it might be inferred that dietary toxins play an important selection driver shaping between-species Tas $2 r$ diversity. Our pig population genomic analysis showed that Tas2rs exhibited higher nucleotide diversity than both fatty acid and amino acid receptors (Tables 3 and 4). In addition, this gene variability is higher than the normally reported for the pig species genome wide. These findings provide additional evidence of the potential role of the bitter taste system in the adaptation, possibly through balancing selection, to various ecological niches in agreement with recent findings related to mammalian species [37].

In general, the high average nucleotide diversity in gene regions compared to intergenic regions for Tas 2 rs was in contrast to the remaining groups of genes, which showed the opposite effect. The incidence and location of the non-synonymous SNPs across the 10 porcine Tas2rs occur with the same frequency in both the transmembrane and non-transmembrane domains indicating that there has been no selection signature for having mutations in predicted ligand binding domains. Among non-synonymous variants, the most potentially deleterious ones, according to the SIFT score, were in general at low frequency (Additional file 2). An interesting exception was that of nsSNP rs330666697 (Tas1r1), with intermediate frequency in Asian domestics and segregating in international breeds as well. The high frequency in Asian domestics but absence in Asian wild boars suggest that this mutation appeared after domestication and that quickly raised in frequency afterwards, may be because its potentially deleterious consequences were offset by other advantages and was positively selected. Further functional studies are required to confirm this hypothesis. Using homology analysis with the TAS1R1 human sequence, the pig SNP rs330666697 is predicted to be located in the first transmembrane helical domain. The polymorphism is unlikely to affect ligand binding because the ligand binding domain in Tas1r1 is located in the extracellular $\mathrm{N}$-terminus $[28,43]$. Furthermore, the amino acid change $\mathrm{L}->\mathrm{V}$ is unlikely to have significant consequences (e.g. protein folding) as both AA are nonpolar, i.e. hydrophobic.

The Asian and European wild boars diverged ca. 1.2 M [2]. This long evolutionary distance results in two highly differentiated clusters when both Asian and European pigs are investigated using, e.g., high density SNP arrays or mitochondrial phylogeny [2,25]. It is therefore noteworthy that Tasr phylogeography departs significantly from the genome wide autosomal pattern and, for these taste receptors, the extreme autosomal Asia - Europe divergence is highly attenuated (Figure 3A). A potential explanation for lack of divergence between Europe and Asia would be the well-known introgression of Chinese pigs into European domestics that occurred as of the 17th century onwards, followed by selection of Chinese haplotypes. Although this has been observed in some genes [44], it is unlikely to be the (main) reason for the pattern observed since a high variability is found across all populations, including European wild boar. Nevertheless, Asian introgression cannot be excluded. To study this issue better, we carried out a PCA and computed neighbor-joining (NJ) trees for each individual gene (results not shown). Interestingly, for the most differentiated gene, Tas2R9 $\left(\mathrm{F}_{\mathrm{ST}}=0.41\right)$, the NJ tree (Additional file 5) does suggest the presence of introgression in Large White and Hampshire, as well as in some Creole pigs,

Assuming that the genome wide pattern is primarily the result of drift, a less than expected differentiation might be explained by some sort of balancing selection at the TR genes. Balancing selection could also explain that variability is higher than genome wide and that remains approximately constant within the Tasrs and the flanking regions (Table 3). A higher than expected variability could be an artifact due to the presence of copy number variants (CNVs) However, this is unlikely in this case since we did not find any overlap between Tasr positions and CNV coordinates reported in the pig genome $[20,45,46]$. In contrast, purifying selection seems also to have played a role in shaping Tasr diversity, given the prevalence of ratios of non-synonymous to synonymous nucleotide diversity $\left(\pi_{\mathrm{a}} / \pi_{\mathrm{s}}\right)$ smaller than one (Table 3 ). These results do not seem to agree, in part, with Groenen et al. [2], who found four taste receptor genes (Tas1r2, Tas2r1, Tas2r40 and Tas2r39) under positive selection $\left(\pi_{\mathrm{s}} / \pi_{\mathrm{a}}\right.$ ratio equal to 1.5 to 1.9$)$. However fewer samples were used in the previous study compared to the current data set, which includes Creole, Brazilian and local Iberian pigs. To verify this result, we also computed other tests for detection of positive selection (i.e. the HKA [47] and the McDonald-Kreitman [48] tests), but none of them were significant (results not presented), suggesting weak or no positive selection pressure.

Genome wide analyses have shown a higher nucleotide diversity in Asia than in Europe, as expected due to the bottleneck experienced by European wild boars when migrating out of Asia [49]. In Asia, a reduced diversity in domestics vs. wild boars was also observed by Bosse et al. [49] and Groenen et al. [2]. Interestingly, this reduction in diversity was not observed for taste receptors neither when comparing Asian vs. European wild boars, 
nor between Asian domestics and wild boars (Table 4, Additional file 3 ). The only population with a marked reduction in diversity was the Iberian breed, and it should be mentioned that the strain sequenced here pertains to a closed population (Guadyerbas) maintained genetically isolated since 1945 [21]. As argued by Esteve-Codina et al. [20], inbreeding due to confinement explains most of loss in variability in this strain, whereas the whole of Iberian strains hold a variability comparable to that found today in European wild boar. The most variable populations were American village pigs (Creole and Brazilian); this apparently surprising finding can be explained by their admixed nature, as these pigs are the result of crossing with many different origins [25].

\section{Conclusions}

We are defining a full GPCR-based nutrient and taste receptor gene repertoire in the pig and a comprehensive analysis of its worldwide variability using shotgun sequence data from 79 domestic and wild pigs of 14 different breeds. The porcine Tasr repertoire in our study consists of 28 genes of which 15 have been identified as bitter taste receptor genes (Tas2rs) of which 4 were pseudo genes. Our findings on Tasrs improve the most recent annotation of the pig genome (Sus scrofa 10.2). In addition, all the researched genes (except Tas2r40, for reasons discussed) were found to be expressed at different levels in pig's tongue circumvallate papillae. Our pig population genomic analysis showed that bitter taste genes had higher nucleotide diversity than either fatty acid or amino acid receptors. The cluster of genes related to bitter taste (Tas2rs) showed the lowest degree of homology with the human repertoire together with the highest nucleotide diversity when compared to the fatty acid and amino acid receptors. These findings are interpreted as evidence of a dynamic eco-evolutionary process between the bitter taste system and dietary adaptation particularly to plant compounds. Interestingly, we also found a much less marked divergence between Asian and European haplotypes than found with genome wide markers; that, together with the high variability, may be indicative of a balancing selection at these loci, in particular for bitter taste receptors.

\section{Methods}

\section{Ortholog identification and verification}

The mRNA sequences of all 25 and 36 known bitter taste receptors for human and mouse respectively were obtained from NCBI. In addition, mRNA sequences for known fatty and amino acid receptors were also collected from human and mouse databases. Each one of these sequences was blasted to the pig refseq genome assembly using the megablast algorithm. Only when no hits were found, was a less conservative method used in a step-wise fashion from discontiguous megablast to the blastn algorithm. Genes were considered orthologous according to the criteria that the identity percentage was equal to greater than $50 \%$. In addition, specific to Tas 2 rs, only genes with a single exon of approximately 300 amino acids in length were considered for the gene expression experiment and SNP analysis.

In order to verify correct annotation of open reading frames of the identified porcine candidate taste receptor genes, the mRNA sequences were downloaded from NCBI and checked as follows. The nucleotides were translated into amino acids using the online software ExPASy (http://www.expasy.org/) [50]. Using this information start and stop sites were up-dated where appropriate and can be seen in Additional file 6.

\section{Gene expression analysis}

The real time PCR assays were carried out according to previously defined requirements [51]. PCR primers were designed in order to specifically amplify unique fragments of each of the pig taste receptor genes that were identified in the BLAST analysis. We acknowledge that the primers for GPR92 were previously published [35]. In addition, primers for the two reference genes, RPLP and $\beta$-actin were also designed. The details of these primers are included in Additional file 6. The specificity of the primers was established by confirming single products of the correct gene was amplified by a PCR blast in NCBI, as well as by the presence of single bands of the correct size of PCR products run on agarose gels. Furthermore, the melt curves from the real time PCR reactions were singular and sharp, indicating single products, with no evidence of secondary structures that could inhibit the PCR. The relative gene expression levels were estimated using the Pfaffl method [52] which involved taking into account the cycle threshold (CT) values of both the candidate genes and of the two reference genes, as well as taking into account the efficiency of each of the primer sets. These normalized values were then standardized to a calibrator assay, Tas1r1 expression in the circumvallate papillae. In order to identify which of the receptor genes identified in the pig taste repertoire are expressed, tongue tissues were collected from 6 newly weaned piglets ( $24 \pm 3$ days of age and $9.367 \pm 2.7 \mathrm{~kg}$ of body weight) following exsanguination (animal ethics approval: CNFS/217/11/PORK CRC). The 6 piglets ( 3 males) represent biological replicates from the same breed (Large White) and were equally reared following standard pig production practices at the University of Queensland, Gatton piggery. From these tongues, circumvallate papillae were isolated and total RNA was extracted using a TRIZOL-chloroform method, where RNA is purified using a Qiagen RNeasy column, followed by a sodium acetate cleanup step. The RNA was reverse transcribed into cDNA using a Qiagen Reverse transcription kit. 
No-reverse transcription controls were included to ensure that there was no genomic contamination present. The real time qPCR assays were carried out using SYBR green in a $\mathrm{ViiA}^{\mathrm{T}} 7$ Real-Time PCR system (Applied Biosystems, Life Technologies).

\section{Sampling and sequencing}

Whole genome shotgun sequences of 77 pigs from international, American Creole, European and Asian domestic breeds, Asian and European wild boars was analyzed in this study. We also included two Sumatran wild boars as out-groups. Of those sequences, 54 were downloaded from SRA accession numbers $[20,27,53,54]$ and 25 are unpublished. New sequences were obtained with HiSeq Illumina's technology, paired end reads of 100 base pairs (bp) long. The new genomes, primarily Iberian pigs and American village (Creole) pigs, were a subset of those described previously [25]. Samples were grouped into international (comprising the well-known highly selected breeds Large White, Landrace, Duroc, Pietrain and Hampshire), Creole (village) pigs from several American countries, local breeds from Brazil (Moura, Monteiro and Piau), Chinese breeds (Meishan, Xiang, Jiangquhai and Wuzhishan) and Wild Boars from Europe and Asia (Table 2). We directly downloaded the aligned bam files for the samples in [53]; for the remaining sequences, we aligned the reads using Burrows Wheeler Alignment tool (BWA) [55] allowing for 7 mismatches per $100 \mathrm{bp}$ long read.

\section{SNP calling and annotation}

Pig candidate genes analyzed in this study included all 21 available taste receptors in assembly Sus scrofa genome built 10.2 for bitter (Tas2r7, Tas2r9, Tas $2 r 10$, Tas2r16, Tas2r20, Tas2r38, Tas2r39, Tas2r40, Tas $2 r 41$, Tas2r42 and Tas2r60), amino acid receptor (GPRC6A, mGluR1, mGluR4, Tas1r3, Tas1r1 and CaSR) and fatty acid receptors (GPR40, GPR43, GPR41, GPR120 and GPR84). Six genes were excluded from the analysis (Tas1r2, Tas2r1, Tas2r134, Tas2r3, Tas2r4 and GPR92), because they were not present in the official assembly or were in isolated scaffolds.

First, single nucleotide polymorphisms (SNPs) were called for each sample individually using SAMtools v.0.0.18 mpileup function [55], filtering by base and mapping qualities of at least 20. Minimum and maximum depths were set to five and twice the average depth per sample, respectively. The Variant Call Format files version 4.0 (VCF) resulting from the SNPs calling were then merged into a multi individual VCF using custom Perl scripts. For missing positions, the bam files were inspected to check whether the reference allele was present (always filtering by the same quality criteria as above) and the VCF file was completed if possible. Otherwise the position was treated as missing. After obtaining the joint VCF file, the region of interest of the 21 candidate genes distributed among pig chromosomes $1,5,6,7,13,14$ and 18 were obtained to analysis from these smallest windows, and $10 \mathrm{~kb}$ flanking regions according to reference gene coordinates (Sus scrofa 10.2) were added. If two genes were closer than $20 \mathrm{~kb}$, the intergenic region was split in half and 'assigned' to each corresponding gene.

Each SNP was annotated with Variant Effect Predictor (VEP) perl script tool available in Ensembl http://www. ensembl.org/info/docs/tools/vep/index.html [56], using Ensembl database v. 72. This was done only for those genes (Tas2r9, Tas2r39, Tas2r41, Tas2r60, GPRC6A, mGluR1, mGluR4, Tas1r1, Tas2r3, CaSR, GPR40, GPR43, GPR41, GPR120 and GPR84) where the official annotation coincided with our manually obtained annotation. Standard settings including the options Sorting Intolerant From Tolerant (SIFT), to predict the effect of amino acid substitution on protein function [57] for non-synonymous SNPs (nsSNPs), and to check for existent co-located variants that returns the reference SNP ID number (rsID) from database of SNP (dbSNP) were included. For the remaining genes, SNP class (in intergenic, exonic, intronic, and in untranslated regions (UTRs) as well as consequence of variations in transcripts), was assessed either manually or with mstatspop program v.0.998978b, S. Ramos-Onsins, unpublished, available at http://bioinformatics.cragenomica. es/numgenomics/people/sebas/software/software.html). A customized GFF3 v3 file and FASTA files corresponding to each gene were generated using custom PERL scripts. The FASTA files, where missing positions are replaced by N's, were used as input for mstatspop program.

\section{Statistics analysis}

We calculated the global and by population allele frequency for each SNP with VCF tools program version 0.1.11 [58] and the mstatpop program was used to estimate percentage of missing data and diversity parameters such as total nucleotide diversity $\left(\pi_{t}\right)$, i.e., considering the full region that included genic and intergenic region, genic $\left(\pi_{\mathrm{g}}\right)$, intergenic region $\left(\pi_{\text {int }}\right)$, intron $\left(\pi_{\mathrm{i}}\right)$, exons $\left(\pi_{\mathrm{e}}\right)$ for genes with more than one exon (for those genes with only one exon the nucleotide diversity is the same found in genic region), and in UTRs regions $\left(\pi_{\mathrm{utr}}\right)$. The rate of synonymous $\left(\pi_{\mathrm{s}}\right)$ and non-synonymous $\left(\pi_{\mathrm{a}}\right)$ variability rates were performed to investigate selection pressure on taste receptor genes $\left(\pi_{\mathrm{a}} / \pi_{\mathrm{s}}\right)$. A $\omega=\pi_{\mathrm{a}} / \pi_{\mathrm{s}}$ ratio $>1$ is indicative of a long term pattern of positive selection, whereas less than one suggest purifying selection, and a ratio of one may indicate neutrality [59]. Fixation index $\left(\mathrm{F}_{\mathrm{ST}}=1-\pi_{\mathrm{iw}} / \pi_{\mathrm{it}}\right)$, where $\pi_{\mathrm{iw}}$ is the average number of different nucleotides between two sequences within populations and $\pi_{i t}$ is the number of different nucleotides in the whole population was obtained. Its significance was computed with 1000 
permutations. Approximate standard errors (SE) of nucleotide diversities for each gene were obtained by generation of 95\% confidence interval (CI) including 1000 random samples and using by default an intermediate recombination rate model $(\mathrm{R}=10)$ using the neutral coalescent simulator in DnaSP v5 [60]. For these simulations, we used estimates of nucleotide variability, diversity and number of sites corrected for missing computed with mstatspop.

Principal component analysis (PCA) was conducted in $\mathrm{R}$ software [61] (http://cran.rproject.org) with PLINK format files [62] extracted from VCF file using a custom Perl script. This analysis was performed on the full SNPs set and on the non-synonymous sites set as well as on the different genes groups (bitter, amino acid and fatty acid taste receptors) to study genetic structure of the population. We also investigated the genetic relationships with STRUCTURE version 2.3.4 [22]. We performed a structure analysis with two sets of SNPs in bitter taste receptor genes: (1) including only nsSNP and (2) a set composed of SNPs from noncoding and coding region. We performed five permutations for each number of populations (K) that ranged from 1 to 15 with 100,000 MCMC (Markov chain Monte Carlo) and a burning period of 10,000 steps and employed admixture and correlated allele frequency parameters. The significant $K$ number of different genetic clusters was obtained by the Delta K statistic [63] which was calculated using STRUCTURE HARVESTER version 0.9.93 [64]. Genetic distances were calculated with PLINK software using the SNPs data from each gene, and then we used this information to create Neighbor-Joining trees using R. The trees will help us to visualize the genetic differences between the individuals from different locations and breeds in the world, as well as if there was indication of Asian haplotypes into international pig breeds as a result of the introgression process.

\section{Ethics Statement}

Animal care and procedures were performed following the Australian Animal Welfare Standards and Guidelines (http://www.daff.gov.au/animal-plant-health/welfare/ standards-guidelines) [65] and approved by the Animal Ethics Committee of the University of Queensland (Approval Certificate: CNFS/217/11/PORK CRC).

\section{Availability of supporting data}

New SNPs identified have been submitted to dbSNP (accession application in progress).

\section{Additional files}

Additional file 1: The $\mathbf{2 8}$ taste receptor genes identified for the pig. Shown is the gene annotation information from NCBI, as well as a summary of the BLAST results for the human and mouse genomes.
Additional file 2: Complete list of SNPs, with rs id if in dbSNP gene, position, alternative allele, SIFT prediction for non-synonymous changes, and allele frequency by population. SIFT score $\leq 0.05$ is considered as potentially deleterious in the protein function and values $>0.05$ are tolerated

Additional file 3: Nucleotide diversity for total $\left(\pi_{t} \times 10^{3}\right)$ and genic region $\left(\pi_{g} \times 10^{3}\right)$ by population.

Additional file 4: The General Feature Format (GFF) file used as input for analysis of SNPs. ${ }^{*}$ denotes updates compared to current annotation.

Additional file 5: NJ tree of genetic distances for Tas2R9 gene. Color triangles represent population origins: INT, International; IB, Iberian; CR, Creole; BR, Brazilian; ASD, Asian domestic; ASWB, Asian wild boar; EUWB, European wild boar; SWB, Sumatran wild boar. The first two letters of each sample are the breed code: CR, creole; LR, Landrace; LW, Large White; IB, Iberian; HA, Hampshire; XI, Xian; MS, Meishan; JQ, Jianquahi; TW, Tamworth; DU, Duroc. Note, eg, that six out of 14 LW samples cluster near Asian samples, together with some Creole and Pietrain individuals.

Additional file 6: Primer details for the porcine nutrient sensing and taste receptor genes used for estimating relative gene expression levels.

\section{Abbreviations}

ACTB: Beta-actin gene; ASD: Asian domestic population; ASWB: Asian wild boar population; ca: Circa (approximately); Cl: Confidence interval; CNV: Copy number variant; CR: Creole population; EUWB: European wild boar population; GPCR: G-Protein coupled receptor; IB: Iberian population; INT: International population; mtDNA: Mitochondrial DNA; MYA: Million years ago; NJ: Neighbor-joining; NGS: Next generation sequence; Ns: Nonsynonymous; nsSNP: Non-synonymous single nucleotide polymorphism; PCA: Principal component analysis; PUFA: Polyunsaturated fatty acid; qPCR: Quantitative PCR; RPLP: Ribosomal subunit protein gene; SIFT: Sorting Intolerant from tolerant; Sy: Synonymous; TR: Taste receptor gene; Tasr: Nutrient sensing and taste receptor gene; Tas 1 rs: Family 1 taste receptor genes; Tas2rs: Family 2 taste receptor genes; $\mathrm{t}_{\mathrm{i}} / \mathrm{t}_{\mathrm{v}}$ : Average rate of transitions vs transversions; T1R: Family 1 taste receptor; T2R: Family 2 taste receptor; UTR: Untranslated region; VCF: Variant call format; VEP: Variant effect predictor; WB: Wild boar population; $\Pi_{s}$ : Synonymous variability rate; $\Pi_{\mathrm{a}}$ : Non-synonymous variability rate.

Competing interests

The authors declare that they have no competing interests.

\section{Authors' contributions}

ER and MPE conceived the original concepts and experimental hypothesis and designed the experiment. NDJ was involved with defining the candidate gene list, generating the GFF input file for the meta-analysis and the GPCR study. ECDS carried out the analysis of NGS data, with help from WBP. AR participated in the interpretation of results and discussion. ER, MPE, NDJ and ECBS wrote the manuscript with help from AR. All authors read and approved the final manuscript.

\section{Acknowledgements}

We thank Mowen Zhan and Marcin Rzepus for carrying out qPCR assays and the statistical analysis of the corresponding result. We thank S.E. Ramos-Onsins for help with his mstatpop program and many discussions, E. Bianco for extracting the relevant gene regions, B. Nevado for scripts and S.R. Paiva and EMBRAPA-CENARGEN (Brazil) for sharing samples. Work funded in part by the UQ New Staff Research Start-Up Fund to ER, and AGL2010-14822 grants (Spain) to MPE. ECS is funded by CNPq (Ciência sem Fronteiras Program, Brazil), CAPES and WBP, by COLCIENCIAS (Francisco José de Caldas fellowship 497/2009, Colombia).

The preliminary description of the porcine taste receptor repertoire was presented at the Australian Pig Science Association 2013 meetings [14].

\section{Author details}

${ }^{1}$ Centre for Research in Agricultural Genomics (CRAG), CSIC-IRTA-UAB-UB, 08193 Bellaterra, Spain. '2Faculty of Agronomy and Veterinary Medicine, Darcy Ribeiro UnB, Brasília-Asa Norte, Distrito Federal 70.910-970, Brazil. ${ }^{3}$ Centre for 
Nutrition and Food Sciences, The University of Queensland, St. Lucia 4067 Australia. ${ }^{4}$ Commonwealth Scientific and Industrial Research Organisation (CSIRO), Agriculture Flagship, Queensland Bioscience Precinct, 306 Carmody Road, St. Lucia, QLD 4067, Australia. ${ }^{5}$ nstitut Català de Recerca i Estudis Avançats (ICREA), Carrer de Lluís Companys 23, Barcelona 08010, Spain.

Received: 25 August 2014 Accepted: 13 November 2014 Published: 3 December 2014

\section{References}

1. Frantz LA, Schraiber JG, Madsen O, Megens HJ, Bosse M, Paudel Y, Semiadi G, Meijaard E, Li N, Crooijmans RP, Archibald AL, Slatkin M, Schook LB, Larson G, Groenen MA: Genome sequencing reveals fine scale diversification and reticulation history during speciation in Sus. Genome Biol 2013, 14(9):R107.

2. Groenen MA, Archibald AL, Uenishi H, Tuggle CK, Takeuchi Y, Rothschild MF, Rogel-Gaillard C, Park C, Milan D, Megens HJ, Li S, Larkin DM, Kim H, Frantz LA, Caccamo M, Ahn H, Aken BL, Anselmo A, Anthon C, Auvil L, Badaoui B, Beattie CW, Bendixen C, Berman D, Blecha F, Blomberg J, Bolund L, Bosse M, Botti S, Bujie Z, et al: Analyses of pig genomes provide insight into porcine demography and evolution. Nature 2012, 491(7424):393-398.

3. Larson G, Dobney K, Albarella U, Fang M, Matisoo-Smith E, Robins J, Lowden S, Finlayson H, Brand T, Willerslev E, Rowley-Conwy P, Andersson L, Cooper A: Worldwide phylogeography of wild boar reveals multiple centers of pig domestication. Science 2005, 307(5715):1618-1621.

4. Larson G, Albarella U, Dobney K, Rowley-Conwy P, Schibler J, Tresset A, Vigne J-D, Edwards CJ, Schlumbaum A, Dinu A, Bălăçsescu A, Dolman G, Tagliacozzo A, Manaseryan N, Miracle P, Van Wijngaarden-Bakker L, Masseti M, Bradley DG, Cooper A: Ancient DNA, pig domestication, and the spread of the Neolithic into Europe. Proc Natl Acad Sci 2007, 104(39):15276-15281.

5. Jones GF: Genetic aspects of domestication, common breeds and their origin. In The Genetics of the Pig. Edited by Rothschild MFRA. Oxon, UK: Wallingford: CAB International; 1998:17-50,

6. Porter V: Pigs: A Handbook to the Breeds of the World. Mountfield: Helm Information Ltd; 1993.

7. Kosiol C, Vinar T, da Fonseca RR, Hubisz MJ, Bustamante CD, Nielsen R, Siepel A: Patterns of positive selection in six Mammalian genomes. PLoS Genet 2008, 4(8):e1000144.

8. Li D, Zhang J: Diet Shapes the Evolution of the Vertebrate Bitter Taste Receptor Gene Repertoire. Mol Biol Evol 2013, 31:303-309.

9. Bachmanov AA, Beauchamp GK: Taste receptor genes. Annu Rev Nutr 2007, 27:389-414

10. Wellendorph $\mathrm{P}$, Johansen LD, Bräuner-Osborne H: Chapter Five - The Emerging Role of Promiscuous 7TM Receptors as Chemosensors for Food Intake. In Vitamins \& Hormones. 84th edition. Edited by Gerald L. Gerald Litwack, Jefferson Medical College, Thomas Jefferson University, Philadelphia, PA, USA: Academic; 2010:151-184.

11. Axelsson E, Ratnakumar A, Arendt ML, Maqbool K, Webster MT, Perloski M, Liberg O, Arnemo JM, Hedhammar A, Lindblad-Toh K: The genomic signature of dog domestication reveals adaptation to a starch-rich diet. Nature 2013, 495(7441):360-364.

12. Archibald AL, Bolund L, Churcher C, Fredholm M, Groenen MA, Harlizius B, Lee KT, Milan D, Rogers J, Rothschild MF, Uenishi H, Wang J, Schook LB: Pig genome sequence - analysis and publication strategy. BMC Genomics 2010, 11:438.

13. Roura E: Taste beyond taste. In Australian Pig Science Association Conference (APSA 2011): 2011. Adelaide, Australia: Australasian Pig Science Association; 2011:106-117.

14. De Jager N, Zhan M, Rzepus M, Roura E: Towards defining the taste receptor repertoire in the pig. In Australasian Pig Science Association Conference (APSA 2013). 47th edition. Edited by Pluske J. Melbourne: Australia: Australasian Pig Science Association; 2013:47.

15. Amaral AJ, Ferretti L, Megens HJ, Crooijmans RP, Nie H, Ramos-Onsins SE, Perez-Enciso M, Schook LB, Groenen MA: Genome-wide footprints of pig domestication and selection revealed through massive parallel sequencing of pooled DNA. PLOS One 2011, 6(4):e14782.

16. Lindblad-Toh K, Winchester E, Daly MJ, Wang DG, Hirschhorn JN, Laviolette $J$, Ardlie K, Reich DE, Robinson E, Sklar P, Shah N, Thomas D, Fan JB, Gingeras T, Warrington J, Patil N, Hudson TJ, Lander ES: Large-scale discovery and genotyping of single-nucleotide polymorphisms in the mouse. Nat Genet 2000, 24(4):381-386.
17. Rosenberg MS, Subramanian S, Kumar S: Patterns of transitional mutation biases within and among mammalian genomes. Mol Biol Evol 2003, 20:988-993.

18. Ferretti L, Raineri E, Ramos-Onsins S: Neutrality tests for sequences with missing data. Genetics 2012, 191(4):1397-1401.

19. NCBI dbSNP Short Genetic Variations. In [http://www.ncbi.nIm.nih.gov/ $\mathrm{SNP} /]$

20. Esteve-Codina A, Paudel Y, Ferretti L, Raineri E, Megens HJ, Silio L, Rodriguez MC, Groenen MA, Ramos-Onsins SE, Perez-Enciso M: Dissecting structural and nucleotide genome-wide variation in inbred lberian pigs. BMC Genomics 2013, 14:148.

21. Toro MA, Rodrigañez J, Silio L, Rodriguez C: Genealogical analysis of a closed herd of Black Hairless Iberian pigs. Conserv Biol 2000, 14(6):1843-1851.

22. Pritchard JK, Stephens M, Donnelly P: Inference of population structure using multilocus genotype data. Genetics 2000, 155:945-959.

23. Yu G, Xiang H, Wang J, Zhao X: The phylogenetic status of typical Chinese native pigs: analyzed by Asian and European pig mitochondrial genome sequences. J Anim Sci Biotechnol 2013, 4(1):9.

24. Yang S, Zhang H, Mao H, Yan D, Lu S, Lian L, Zhao G, Yan Y, Deng W, Shi X, Han S, Li S, Wang X, Gou X: The Local Origin of the Tibetan Pig and Additional Insights into the Origin of Asian Pigs. PLoS One 2011, 6(12):e28215.

25. Burgos-Paz W, Souza CA, Megens HJ, Ramayo-Caldas Y, Melo M, Lemus-Flores C, Caal E, Soto HW, Martinez R, Alvarez LA, Aguirre L, Iniguez V, Revidatti MA, Martinez-Lopez OR, Llambi S, Esteve-Codina A, Rodriguez MC, Crooijmans RP, Paiva SR, Schook LB, Groenen MA, Perez-Enciso M: Porcine colonization of the Americas: a 60 k SNP story. Heredity 2013, 110(4):321-330.

26. Goedbloed DJ, Megens HJ, Van Hooft P, Herrero-Medrano JM, Lutz W, Alexandri P, Crooijmans RPMA, Groenen M, Van Wieren SE, Ydenberg RC, Prins HHT: Genome-wide single nucleotide polymorphism analysis reveals recent genetic introgression from domestic pigs into Northwest European wild boar populations. Mol Ecol 2013, 22(3):856-866.

27. Ramírez O, Burgos-Paz W, Casas E, Ballester M, Bianco E, Olalde I, Novella V, Gut M, Lalueza-Fox C, Saña M, Pérez-Enciso M: Genome data from a 16th century pig illuminate modern breed relationships. Heredity 2014, in press.

28. Xu H, Staszewski L, Tang H, Adler E, Zoller M, Li X: Different functional roles of T1R subunits in the heteromeric taste receptors. Proc Natl Acad Sci U S A 2004, 101(39):14258-14263.

29. Humphrey B, Tedó G, Klasing KC, Roura E: Characterization of porcine umami taste receptors (pT1r1 and pT1r3). In 4lèmes Journées de la Recherche Porcine: 2009; Paris, France. 2009:165-166.

30. Roura E, Humphrey B, Klasing K, Swart M: Is the pig a good umami sensing model for humans? A comparative taste receptor study. Flavour and Fragrance Journal 2011, 26(4):282-285.

31. Kiuchi S, Yamada T, Kiyokawa N, Saito T, Fujimoto J, Yasue H: Genomic structure of swine taste receptor family 1 member 3, TAS1R3, and its expression in tissues. Cytogenet Genome Res 2006, 115(1):51-61.

32. Roura E, Humphrey B, Tedo G, Ipharraguerre IR: Unfolding the codes of short-term feed appetence in farm and companion animals: a comparative oronasal nutrient sensing biology review. Can J Anim Sci 2008, 88(4):535-558.

33. Shi P, Zhang J, Yang H, Zhang YP: Adaptive diversification of bitter taste receptor genes in Mammalian evolution. Mol Biol Evol 2003, 20(5):805-814.

34. Moran AW, Al-Rammahi MA, Arora DK, Batchelor DJ, Coulter EA, Daly K, Ionescu C, Bravo D, Shirazi-Beechey SP: Expression of $\mathrm{Na}+$ /glucose co-transporter 1 (SGLT1) is enhanced by supplementation of the diet of weaning piglets with artificial sweeteners. Br J Nutr 2010, 104(5):637-646.

35. Haid DC, Jordan-Biegger C, Widmayer P, Breer H: Receptors responsive to protein breakdown products in g-cells and d-cells of mouse, swine and human. Front Physiol 2012, 3:65.

36. Colombo M, Trevisi P, Gandolfi G, Bosi P: Assessment of the presence of chemosensing receptors based on bitter and fat taste in the gastrointestinal tract of young pig. J Anim Sci 2012, 90(Suppl 4):128-130.

37. Hayakawa T, Suzuki-Hashido N, Matsui A, Go Y: Frequent Expansions of the Bitter Taste Receptor Gene Repertoire during Evolution of Mammals in the Euarchontoglires Clade. Mol Biol Evol 2014, 31(8):2018-2031.

38. Ballari SA, Barrios-García MN: A review of wild boar Sus scrofa diet and factors affecting food selection in native and introduced ranges. Mamm Rev 2014, 44(2):124-134. 
39. Brown AG, Basell LS, Robinson S, Burdge GC: Site Distribution at the Edge of the Palaeolithic World: A Nutritional Niche Approach. PLoS One 2013, 8(12):e81476.

40. Meyerhof W, Batram C, Kuhn C, Brockhoff A, Chudoba E, Bufe B, Appendino $G$, Behrens M: The molecular receptive ranges of human TAS2R bitter taste receptors. Chem Senses 2010, 35(2):157-170.

41. Herrero-Medrano JM, Megens HJ, Groenen MA, Bosse M, Perez-Enciso M, Crooijmans RP: Whole-genome sequence analysis reveals differences in population management and selection of European low-input pig breeds. BMC Genomics 2014, 15(1):601.

42. Chandrashekar J, Mueller KL, Hoon MA, Adler E, Feng L, Guo W, Zuker CS, Ryba NJP: T2Rs Function as Bitter Taste Receptors. Cell 2000, 100(6):703-711.

43. Li X, Staszewski L, Xu H, Durick K, Zoller M, Adler E: Human receptors for sweet and umami taste. Proc Natl Acad Sci U S A 2002, 99(7):4692-4696.

44. Bosse M, Megens HJ, Frantz LA, Madsen O, Larson G, Paudel Y, Duijvesteijn N, Harlizius B, Hagemeijer Y, Crooijmans RP, Groenen MA: Genomic analysis reveals selection for Asian genes in European pigs following human-mediated introgression. Nat Commun 2014, 5:4392.

45. Ramayo-Caldas Y, Castello A, Pena RN, Alves E, Mercade A, Souza CA, Fernandez Al, Perez-Enciso M, Folch JM: Copy number variation in the porcine genome inferred from a 60 k SNP BeadChip. BMC Genomics 2010, 11:593.

46. Paudel Y, Madsen O, Megens HJ, Frantz LA, Bosse M, Bastiaansen JW, Crooijmans RP, Groenen MA: Evolutionary dynamics of copy number variation in pig genomes in the context of adaptation and domestication. BMC Genomics 2013, 14:449.

47. Hudson RR, Kreitman M, Aguade M: A test of neutral molecular evolution based on nucleotide data. Genetics 1987, 116(1):153-159.

48. McDonald J, Kreitman M: Adaptive protein evolution at the Adh locus in Drosophila. Nature 1991, 351:652-654.

49. Bosse M, Megens HJ, Madsen O, Paudel Y, Frantz LA, Schook LB, Crooijmans $\mathrm{RP}$, Groenen MA: Regions of homozygosity in the porcine genome: consequence of demography and the recombination landscape. PLOS Genet 2012, 8(11):e1003100.

50. ExPASy. [http://www.expasy.org/]

51. Bustin SA, Benes V, Garson JA, Hellemans J, Huggett J, Kubista M, Mueller R, Nolan T, Pfaffl MW, Shipley GL, Vandesompele J, Wittwer CT: The MIQE guidelines: minimum information for publication of quantitative real-time PCR experiments. Clin Chem 2009, 55(4):611-622.

52. Pfaffl MW: A new mathematical model for relative quantification in real-time RT-PCR. Nucleic Acids Res 2001, 29(9):e45.

53. Rubin CJ, Megens HJ, Martinez Barrio A, Maqbool K, Sayyab S, Schwochow D, Wang C, Carlborg O, Jern P, Jorgensen CB, Archibald AL, Fredholm M, Groenen MA, Andersson L: Strong signatures of selection in the domestic pig genome. Proc Natl Acad Sci U S A 2012, 109(48):19529-19536.

54. Fang $X$, Mou $Y$, Huang $Z$, Li $Y$, Han $L$, Zhang $Y$, Feng $Y$, Chen $Y$, Jiang $X$, Zhao W, Sun X, Xiong Z, Yang L, Liu H, Fan D, Mao L, Ren L, Liu C, Wang J, Li K, Wang G, Yang S, Lai L, Zhang G, Li Y, Wang J, Bolund L, Yang H, Wang $J$, Feng $S$, et al: The sequence and analysis of a Chinese pig genome. Gigascience 2012, 1(1):16

55. Li H, Handsaker B, Wysoker A, Fennell T, Ruan J, Homer N, Marth G, Abecasis G, Durbin R, Genome Project Data Processing S: The Sequence Alignment/ Map format and SAMtools. Bioinformatics 2009, 25(16):2078-2079.

56. Flicek PAM, Barrell D, Beal K, Brent S, CarvalhoSilva D, Clapham P, Coates G, Fairley S, Fitzgerald S, Gil L, Gordon L, Hendrix M, Hourlier T, Johnson N, Kähäri AK, Keefe D, Keenan S, Kinsella R, Komorowska M, Koscielny G, Kulesha E, Larsson P, Longden I, McLaren W, Muffato M, Overduin B, Pignatelli M, Pritchard B, Riat HS, Ritchie GR, et al: Ensembl 2012. Nucleic Acids Res 2012, 40(Database issue):D84-D90.

57. Ng PC, Henikoff S: SIFT: predicting amino acid changes that affect protein function. Nucleic Acids Res 2003, 31(13):3812-3814.

58. Danecek P, Auton A, Abecasis G, Albers CA, Banks E, DePristo MA, Handsaker RE, Lunter G, Marth GT, Sherry ST, McVean G, Durbin R, Genomes Project Analysis G: The variant call format and VCFtools. Bioinformatics 2011, 27(15):2156-2158.

59. Zhang Z, Li J, Yu J: Computing Ka and Ks with a consideration of unequal transitional substitutions. BMC Evol Biol 2006, 6:44

60. Librado P, Rozas J: DnaSP v5: a software for comprehensive analysis of DNA polymorphism data. Bioinformatics 2009, 25(11):1451-1452.
61. R Development Core Team: R: A language and environment for statistical computing. R Foundation for Statistical Computing, Vienna, Austria. ISBN 3900051070, URL. 2008. http://www.Rproject.org.

62. Purcell S, Neale B, Todd-Brown K, Thomas L, Ferreira MA, Bender D, Maller J Sklar P, de Bakker PI, Daly MJ, Sham PC: PLINK: a tool set for whole-genome association and population-based linkage analyses. Am J Hum Genet 2007, 81(3):559-575.

63. Evanno G, Regnaut S, Goudet J: Detecting the number of clusters of individuals using the software structure: a simulation study. $\mathrm{Mol}$ Ecol 2005, 14(8):2611-2620.

64. Earl DA, von Holdt BM: STRUCTURE HARVESTER: A website and program for visualizing STRUCTURE output and implementing the Evanno method. Conservation Genetics Resources 2011, 101007/s12686-011-9548-7.

65. Australian Animal Welfare Standards and Guidelines. In [http://www.daff gov.au/animal-plant-health/welfare/standards-guidelines]

doi:10.1186/1471-2164-15-1057

Cite this article as: da Silva et al:: Characterization of the porcine nutrient and taste receptor gene repertoire in domestic and wild populations across the globe. BMC Genomics 2014 15:1057.

\section{Submit your next manuscript to BioMed Central and take full advantage of:}

- Convenient online submission

- Thorough peer review

- No space constraints or color figure charges

- Immediate publication on acceptance

- Inclusion in PubMed, CAS, Scopus and Google Scholar

- Research which is freely available for redistribution 